\title{
Coexistence of porokeratosis ptychotropica with porokeratosis of Mibelli in a Chinese man
}

\author{
Yiping Ma, Chengrang Li, Jianbing Wu, Pangen Cui, Lin Lin, Suying Feng
}

Institute of Dermatology, Chinese Academy of Medical Sciences, Nanjing, China

Head of the Department: Prof. Heng Gu

Porokeratosis represents a spectrum of clinical diseases. Multiple variants have been described including porokeratosis ptychotropica, a rare subtype. The coexistence of two or more variants of porokeratosis in a single patient is regarded as a rare occurrence. Here we report a patient with porokeratosis ptychotropica with coexistent porokeratosis of Mibelli.

The patient was a 47-year-old man who presented with a month's history of pruritic rash on the buttocks. The patient also had an asymptomatic cutaneous eruption involving his right lower part of the buttocks of 20 years' duration. There was no family history of a similar eruption. On physical examination, the patient had perianal erythematous papules and plaques with scale which were coalescent in several locations and extended bilaterally onto the buttocks. The examination also demonstrated satellite papules. His right lower part of the buttocks demonstrated annular patches with a peripheral keratotic ridge. The areas had a diameter of $6 \mathrm{~cm}$ in size (Figure 1).

A skin biopsy of these two different lesions was performed. Histopathological examination of perianal erythematous papules showed characteristic multiple cornoid lamellae (Figure 2). Dyskeratotic cells and focal hypogranulosis were present in the epidermis underlying the column of parakeratosis. The upper dermis contained a mild perivascular lymphocytic infiltrate. No amyloid deposition was seen (Figure 3). The clinical and pathologic findings were compatible with a diagnosis of porokeratosis ptychotropica. The annular patches of his right lower part of the buttocks showed cornoid lamellae at the periphery (Figure 4). Dyskeratotic cells and focal hypogranulosis were present in the epidermis underlying the column of parakeratosis. The annular patches were consistent with a diagnosis of porokeratosis of Mibelli.

Porokeratosis represents a disorder of epidermal keratinization. Its exact aetiology has not been well established but there is increasing evidence that implicates aberrant terminal differentiation of keratinocytes [1].
Porokeratosis is characterized by the cornoid lamella, a column of tightly packed parakeratotic cells that reside within a depression of the epidermis. The cornoid lamella is seen in all variants of porokeratosis, but it is not pathognomonic for the disorder [2].

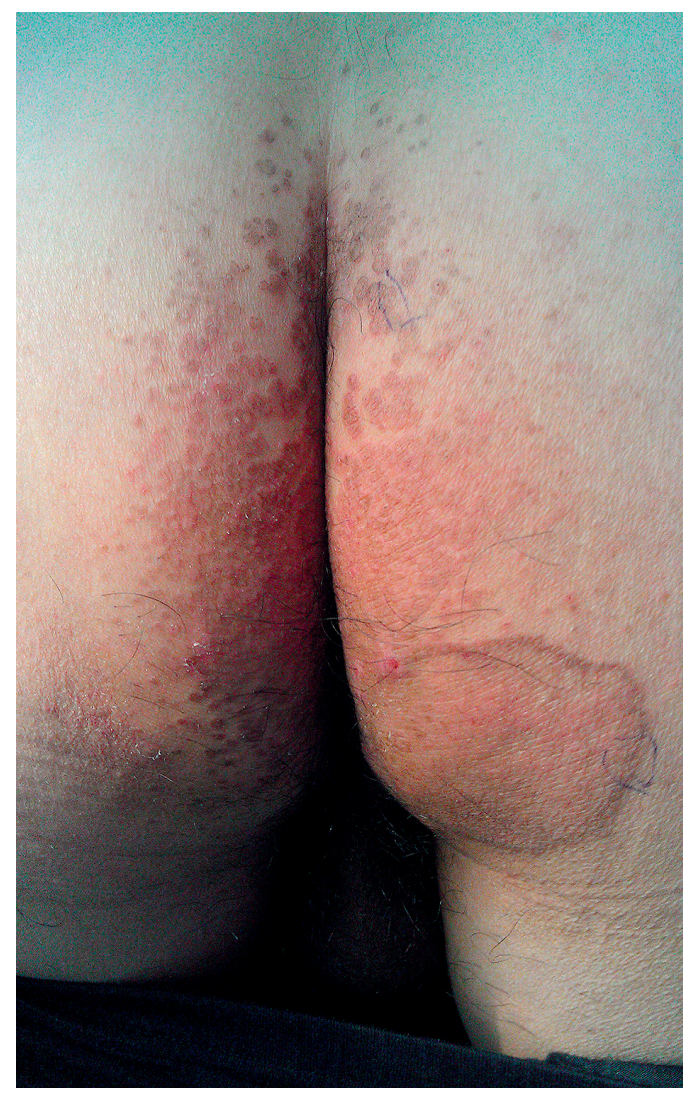

Figure 1. Perianal erythematous papules and plaques with scale which were coalescent in several locations and extended bilaterally onto the buttocks. Annular patches with a peripheral keratotic ridge with a diameter of $6 \mathrm{~cm}$ in size on his right lower part of the buttocks

Address for correspondence: Yiping Ma, Institute of Dermatology, Chinese Academy of Medical Sciences, Nanjing City,

Jiangsu Province Wang Jiang Temple Street No. 12, 210098 Nanjing, China, fax: +86 2583787991, e-mail: mayipingg@sohu.com Received: 26.08.2014, accepted: 18.02.2015. 


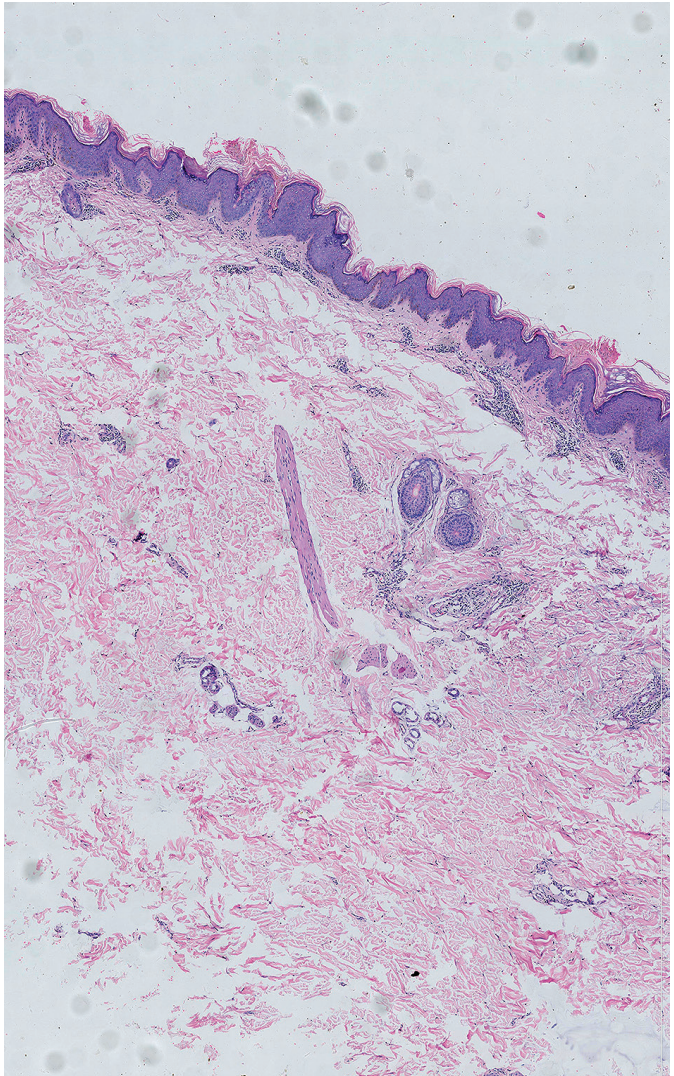

Figure 2. Multiple cornoid lamellae in the epidermis (haematoxylin + eosin $(H+E)$, original magnification $5 \times)$

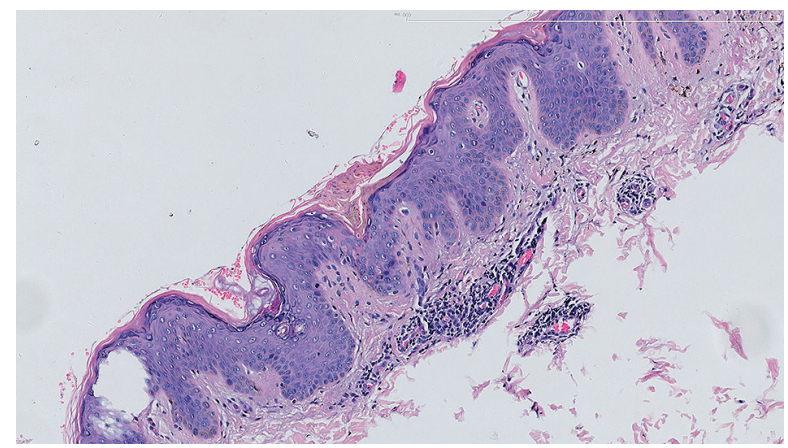

Figure 4. The annular patches of his right lower part of the buttocks show cornoid lamellae at the periphery. Dyskeratotic cells and focal hypogranulosis are present in the epidermis underlying the column of parakeratosis $(\mathrm{H}+\mathrm{E}$, original magnification $10 x$ )

Over a century after Mibelli's first description, the main clinical variants of presently recognized porokeratosis include classic porokeratosis of Mibelli, linear porokeratosis, disseminated superficial (actinic) porokeratosis, porokeratosis Palmaris et plantaris disseminate and punctate porokeratosis. Besides these main clinical variants, a number of rare morphological forms, such

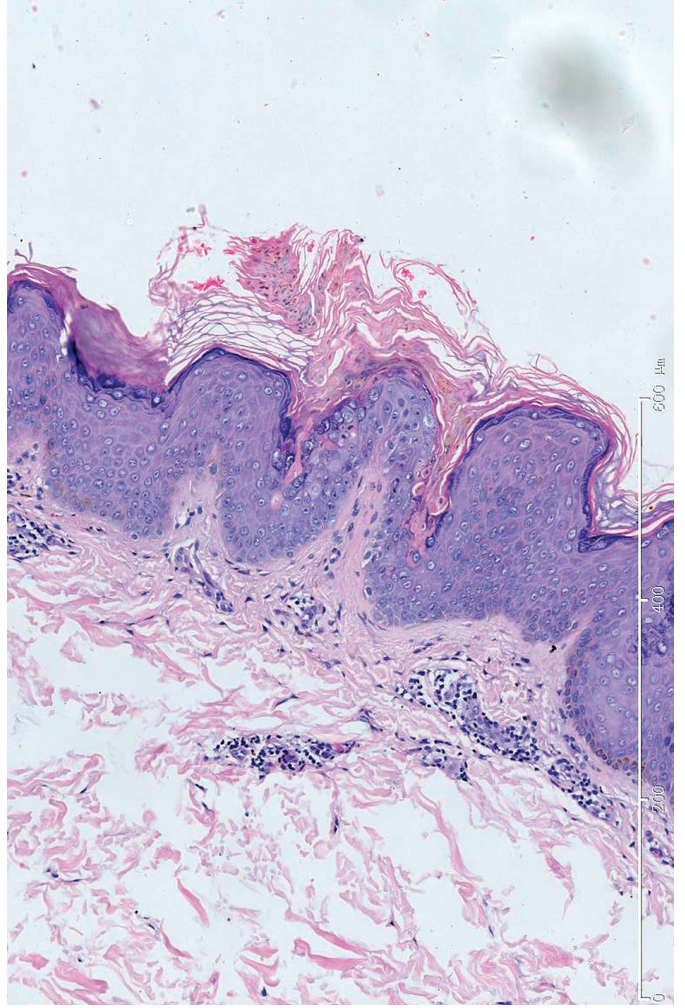

Figure 3. Dyskeratotic cells and focal hypogranulosis present in the epidermis underlying the column of parakeratosis. The upper dermis contains a mild perivascular lymphocytic infiltrate $(\mathrm{H}+\mathrm{E}$, original magnification 10x)

as facial porokeratosis, giant porokeratosis, punchedout porokeratosis, hypertrophic verrucous porokeratosis (HVP), reticulate porokeratosis, eruptive pruritic papular porokeratosis or porokeratosis ptychotropica have been reported in the literature [3].

Porokeratosis ptychotropica was initially described by Lucker et al. in 1995 [4]. The classical description of porokeratosis ptychotropica is a symmetrical pruritic eruption comprising of erythematous papules and plaques localized to the perinatal cleft and extending to the buttocks. There is a tendency for lesions to coalesce centrally and there is expansile growth with the formation of satellite lesions at the periphery. The classical histopathologic feature is the finding of multiple cornoid lamellae. This feature is central to the diagnosis and differentiates this variant from the classical case of porokeratosis of Mibelli in which the cornoid lamellae are typically located at the periphery [5]. It has been proposed that the presence of multiple cornoid lamellae may contribute to its hyperkeratotic and verruciform appearance. The characteristic symptoms of pruritus and the distinctive histopathologic feature of multiple cornoid lamellae, in conjunction with a predilection for the genito-gluteal region and occasional regional extension into the groin and upper thighs, 
constitute features that characterize the diagnosis of porokeratosis ptychotropica.

Our case suffered from porokeratosis ptychotropica with coexistent porokeratosis of Mibelli, the clinical and pathological features fit well with the above characteristics.

Coexistent variants of porokeratosis in a single patient have been described in the classical forms of porokeratosis albeit rarely [6]. This phenomenon is also seen in reported cases of porokeratosis ptychotropica where both classical and non-classical forms of porokeratosis have been shown to concomitantly occur in the same patient. Verma reported a rare case of porokeratosis ptychotropica and coexistent linear porokeratosis in a 10-year-old boy [7].

On a parallel with classical porokeratosis, treatment of porokeratosis ptychotropica has been recognized to be fraught with dissatisfaction. Topical therapies such as corticosteroids, immunomodulators (imiquimod, tacrolimus, 5-fluorouracial) and topical and oral retinoids have at best yielded partial response directed toward symptomatic improvement with little effect on the lesion itself. Dermabrasion has also been utilized with recurrence in one case. There have been mixed results with the carbon dioxide $\left(\mathrm{CO}_{2}\right)$ laser. Surgical approaches have also been attempted with better success [2]. Our patient was treated with topical retinoid creams and oral acitretin, but the lesions showed little improvement and a temporary relief of itch.

In conclusion, we report a further case of the rare porokeratosis variant of porokeratosis ptychotropica with the aim of increasing awareness of this distinct porokeratosis subtype. The case has two different types of porokeratosis simultaneously on the buttocks, and contributes to clinicians' distinguishing them.

\section{Conflict of interest}

The authors declare no conflict of interest.

\section{References}

1. Kamata Y, Hideki M, Watarai A, et al. Expression of bleomycin hydrolase in keratinization disorders. Arch Dermatol Res 2012; 304: 31.

2. Yeo J, Winhoven S, Tallon B. Porokeratosis ptychotropica: a rare and evolving variant of porokeratosis. J Cutan Pathol 2013; 40: 1042-7.

3. Sertznig P, von Felbert V, Megahed M. Porokeratosis: present concepts. J Eur Acad Dermatol Venereol 2012; 26: 404-12.

4. Lucker GP, Happle R, Steijlen PM. An unusual case of porokeratosis involving the natal cleft: porokeratosis ptychotropica? Br J Dermatol 1995; 132: 150-1.

5. McGuigan K, Shurman D, Campanelli C, Lee JB. Porokeratosis ptychotropica: a clinically distinct variant of porokeratosis. J Am Acad Dermatol 2009; 60: 501-3.

6. Sertznig P, von Felbert V, Megahed M. Porokeratosis: present concepts. J Eur Acad Dermatol Venereol 2012; 26: 404-12.
7. Verma SB. A rare case of porokeratosis ptychotropica and coexistent linear porokeratosis in a 10-year-old boy. Clin Exp Dermatol 2009; 34: e501-2. 